Running head: MEASURING INTEGRATED REGULATION

The Development of a Scale Measuring Integrated Regulation in Exercise

Full citation:

McLachlan, S., Spray, C., \& Hagger, M. S. (2011). The development of a scale measuring integrated regulation in exercise. British Journal of Health Psychology, 16, 722-743. doi: $10.1348 / 2044-8287.002009$ 


\begin{abstract}
Objectives. This research aimed to develop and validate a measure of integrated motivational regulation based on self-determination theory in an exercise context. Design. Cross-sectional and prospective surveys were employed. Methods. The measure was developed from first principles from an initial item pool and items were selected using expert evaluators. The validity of the final item pool was tested across high- and lower-active samples $(\mathrm{N}=488)$ using single- and multi-sample confirmatory factor analyses. Results. Analyses supported the factorial, nomological, discriminant, and predictive validity of the scale. Conclusions. The validity of the integrated regulation measure was supported. Present analyses provide evidence that the scale is a valid and reliable tool that may be used to evaluate the effectiveness of autonomy-supportive interventions in health-related behavioural contexts.
\end{abstract}




\section{The Development of a Scale Measuring Integrated Regulation in Exercise}

Epidemiological evidence has shown that low levels of physical activity are associated with a range of chronic health conditions such as coronary heart disease, diabetes, obesity, and cancer (e.g., Hu et al., 2005; Mokdad et al., 2003). However, despite evidence of the health benefits of regular physical activity, a large percentage of the populations in Western European countries do not take sufficient exercise to confer health benefits (Department of Health, 2004; James, Rigby, \& Leach, 2004). Motivation has been identified as an important factor in order to understand the uptake of, and adherence to, exercise behaviour (e.g.; Ryan, Frederick, Lepes, Rubio, \& Sheldon, 1997; Thegersen-Ntoumani \& Ntoumanis, 2006). It is therefore valuable to identify the motivational factors underlying this behaviour and to map the processes by which these factors influence self-regulation, behavioural engagement, and associated outcomes (Hagger, Wood, Stiff, \& Chatzisarantis, 2009, 2010). Valid and reliable measures of social psychological constructs are necessary here, in order to both evaluate the psychological predictors of health behaviour and determine the mediating variables through which health-promoting interventions incur effects (Hagger, 2010).

\section{Self-Determination Theory}

Self-determination theory (SDT; Deci \& Ryan, 2000) provides a dialectic, organismic account of human motivation that has been adopted to explain influences on health related behaviour in a number of domains (e.g., Williams et al., 2006) including physical activity (e.g., Hagger, Chatzisarantis, \& Biddle, 2002). The theory makes a broad distinction between intrinsic and extrinsic motivation. Intrinsic motivation describes participation in behaviour for reasons of interest, enjoyment or satisfaction inherent in that behaviour. Extrinsic motivation makes reference to participation in a behaviour for reasons or rewards separable from the behaviour itself, such as obtaining approval from others. The theory also specifies a state of amotivation, which refers to "a state of lacking any intention to engage in behaviour" (Markland \& Tobin, 2004, p.191). 
In SDT, intrinsically-motivated behaviour is viewed as being driven by the organism's desire to satisfy three fundamental psychological needs: competence, autonomy, and relatedness. Humans are viewed as active agents in the pursuit of fulfilment of these needs (Deci \& Ryan, 2000). SDT comprises several sub-theories that specify key corollaries of the overall theory. Organismic integration theory (OIT, Deci \& Ryan, 1991) specifies a regulatory continuum that not only differentiates intrinsic from extrinsic motivation but also subdivides extrinsic motivation into four types of behavioural regulation distinguished by their level of self-determination or autonomy. The regulatory continuum is shown in Figure 1. Intrinsic motivation falls at one end of the continuum and external regulation lies at the other. Intrinsic motivation represents the prototypic instance of self-determined motivation, while external regulation reflects the prototypic form of extrinsic motivation and is characterised by behavioural engagement for reasons entirely external to the self, for instance to attain tangible rewards or meet externally-imposed deadlines (Ryan \& Deci, 2000). Three further types of extrinsic motivation lie along the continuum according to the degree to which they have been internalised in striving to service psychological needs: introjected, identified, and integrated regulations.

Introjected regulation is the least autonomous form of extrinsic regulation. This refers to behavioural performance in order to avoid negative affective states, such as guilt and shame, or to enhance feelings of self-worth. Behaviour that is governed by introjected regulation is not accepted as one's own, although the regulation is partially internalised. Identified regulation lies adjacent to introjected regulation and refers to pursuit of behaviour to attain personallyvalued outcomes rather than for enjoyment or interest in the activity. Finally, integrated regulation falls adjacent to intrinsic motivation on the continuum and represents the most complete internalisation of a behaviour, such that the behaviour is entirely assimilated as part of the genuine self. This is the most autonomous form of extrinsic motivation. 
- Insert Figure 1 about here -

Pelletier, Dion, D’Angelo, and Reid (2004) suggested that behavioural persistence in striving for desired outcomes is dependent not only on the strength of the motives driving behaviour but also on accepting the regulation for behavioural change as self-determined rather than perceiving it as arising from internal or external pressure. Empirical evidence in the domain of exercise supports this argument as autonomous forms of behavioural regulation have been associated with the maintenance of exercise behaviour over time (e.g., Pelletier, Fortier, Vallerand, \& Briere, 2000; Thøgersen-Ntoumani \& Ntoumanis, 2006).

\section{Previous Measures of Integrated Regulation}

Previous SDT-based research in the health-related behaviour domain has often omitted the full spectrum of constructs from the regulatory continuum. The Sport Motivation Scale (SMS; Pelletier et al., 1995), Behavioural Regulation in Exercise Questionnaire (BREQ; Mullan, Markland \& Ingledew, 1997), and the revised BREQ (BREQ-2; Markland \& Tobin, 2004) omitted subscales for integrated regulation and do not therefore offer a complete operationalisation of motivational constructs specified by OIT. Studies adopting such measures have therefore excluded integrated regulation as a predictor of exercise uptake and adherence (e.g., Edmunds, Ntoumanis, \& Duda, 2006; Ingledew, Markland \& Sheppard, 2004; Wilson \& Rodgers, 2004). Integrated regulation has also been omitted from research adopting the regulatory continuum in other domains such as education (Fairchild, Horst, Finney \& Barron, 2005).

Decisions to omit integrated regulation from SDT-based instruments in the exercise domain have been based on previous research suggesting that it is not a salient construct in decisions to participate in exercise (e.g., Pelletier et al., 1995). The omission of integrated regulation from empirical research also seems to stem from difficulties in establishing discriminant validity between this construct, intrinsic motivation, and identified regulation. Mallett, Kawabata, Newcombe, Otero-Forero, \& Jackson (2007) experienced such 
problems in their revision of the SMS (SMS-6), in which three intrinsic motivation factors (intrinsic motivation to know, to experience stimulation, and to accomplish) were collapsed to form a single factor and an integrated regulation factor was added. Nevertheless, despite some cross-loadings, this revised SMS elicited a more parsimonious and better-fitting factor structure consistent with SDT than the original scale.

Modifications of existing measures in exercise to include integrated regulation have not resulted in definitive measures of the construct, for example Li's (1999) Exercise Motivation Scale (EMS). Wilson, Rodgers, and Loitz (2006) highlighted that the EMS development precluded definitive conclusions on psychometric validity and reliability of the integrated regulation items and expressed concern at the failure of the EMS to conform to the expected simplex-type pattern of associations among constructs. The simplex-like structure of the continuum refers to the expectation that constructs located adjacent to each other will exhibit strong positive relationships, while constructs situated further apart will show weaker positive associations and constructs at opposite poles will be unrelated or negatively related.

Wilson and colleagues developed a four-item measure of integration for use in exercise contexts. Confirmatory factor analyses provided support for the measure and demonstrated that perceived psychological need satisfaction was positively associated with a composite measure of autonomous motivation incorporating the integration items. Wilson and colleagues also claimed criterion validity for their integrated regulation scale as it contributed uniquely to the prediction of exercise behaviour. However, the scale had some limitations. First, it was not developed from first principles, i.e. from a definitive pool of items that captured the essence of the integrated regulation concept. Consequently, items did not reflect how closely bound integrated regulation is to the self. Second, detailed descriptions of the selection of items from theoretical specifications and the process of scale development were not provided. Third, evaluation relied heavily on homogeneous undergraduate psychology student samples, limiting the generalizability of findings. Fourth, the assessment of nomological validity was confined 
largely to associations of the integrated item scores with the need satisfaction portion of SDT's nomological network, rather than assessing relationships with a wider range of theoretically related constructs.

Information regarding the addition of an integrated regulation subscale to the Physical Activity Regulation Scale (D’Angelo, Reid, \& Pelletier, 2007) was also sparse, with no details of item development or validation processes. In contrast, Lonsdale, Hodge, and Rose (2008) developed a measure of integrated regulation within their Behavioral Regulation in Sport Questionnaire (BRSQ), which demonstrated internal consistency, test-retest reliability, and factorial and nomological validity. This scale is, however, limited in its application to competitive sport in a specialist population.

\section{Need for a Valid and Reliable Measure of Integrated Regulation}

Despite some indications that integrated regulation is not a pertinent motivational factor underlying behaviour in certain populations (Pelletier et al., 1995), research has supported the role of integrated regulation in predicting intended and actual behavioural effort (Deci \& Ryan, 1991) and its importance as a key source of motivation in elite athletes (Mallett \& Hanrahan, 2004). A measurement instrument incorporating integrated regulation alongside the remaining behavioural regulation types from OIT would enable researchers to gain a more complete explanation of motivational factors underlying leisure-time exercise and therefore demonstrate superior predictive validity. Third, valid and reliable measures of integrated regulation are necessary to evaluate the effects of health-related behaviour change interventions aiming to facilitate the integration of externally-regulated behaviour (e.g., Chatzisarantis \& Hagger, 2009). The accurate assessment of integrated regulation would also clarify the role of the construct as a mediator of exercise behaviour change and therefore enable the important process of mapping components of an intervention that are effective in changing behaviour to theoretical constructs (Abraham \& Michie, 2008).

\section{The Present Study}


The present investigation details the development of an integrated regulation scale to use in conjunction with existing measures of intrinsic, identified, introjected, and external regulations and amotivation in an exercise context. The scale can be differentiated from the BRSQ (Lonsdale et al., 2008), as it aims to assess motivation for leisure-time exercise, rather than motivation for competitive sport in a specialist population. The scale was developed from first principles using an initial item pool and a rigorous a priori, hypothesis-testing approach. The content, construct, discriminant, nomological, and predictive validity of the measure were tested. A more diverse sample was employed than in previous studies to lend further support for scale validity using a known group differences approach. This was achieved by comparing scores on high- and lower-active sub-samples, in order to determine the factorial invariance of the scale across two groups of individuals who were likely to differ in their degree of integrated regulation.

The research hypotheses were as follows:

(1) The integrated regulation scale is expected to show discriminant validity with all factors on the continuum, including the most proximal constructs of intrinsic motivation and identified regulation. Integrated regulation scale items are hypothesized to load solely on the expected latent factor in confirmatory factor analyses with no cross-loadings on factors representing intrinsic motivation and identified regulation.

(2) A simplex-like pattern of relationships will emerge among the regulatory constructs, such that constructs situated in closer proximity on the continuum will exhibit stronger associations than constructs situated further away. This will provide evidence of the nomological validity of the integrated regulation scale and situate it appropriately relative to the other constructs.

(3) Nomological validity for integrated regulation will also be evaluated through significant and positive associations of integrated regulation with vitality, life-satisfaction, and pertinent facets of flow. Integrated regulation will additionally exhibit discriminant validity 
with these constructs. It is expected that the integrated regulation scale will exhibit strong associations with these factors, following previous research in a sports context that has shown strong positive associations between autonomous forms of behavioural regulation and vitality (Pelletier \& Sarrazin, 2007), life satisfaction (Pelletier et al., 2004), and flow (Mallett et al., 2007).

(4) Integrated regulation will account for a significant proportion of variance in prospective exercise behaviour, beyond that accounted for by the other regulatory constructs while statistically controlling for age.

(5) The structure of the model specifying integrated regulation and the remaining regulatory constructs will be invariant across a high-active sample and a lower-active sample, as evidenced through the minimum criteria of invariance of factor structure and factor loadings.

(6) There will be significant differences between the high-active sample and loweractive sample in terms of latent factor means. Specifically, it is hypothesised that the highactive sample will report significantly higher levels of integrated regulation than the loweractive sample.

\section{Method}

\section{Participants}

The composition of the sample was as follows: 60 participants were undergraduates in engineering sampled from a University in the UK (12\%), 176 were healthy adult members of the general population recruited from community groups and businesses in the UK (36\%), 184 were undergraduates in sports science sampled from another University in the UK (38\%), and 68 were A-level students (14\%), sampled from one sixth form college in the UK (total $\mathrm{N}=$ 488, Males $=191$, Females $=279, M$ age $=21.03, S D=7.53)$. Thirteen participants did not report their gender and data on age were missing for three participants. The sports science students constituted the high-active sample. An independent-samples $t$-test confirmed that the mean level of past physical activity was significantly greater in this group $(M=4.32, S D=$ 
$1.65)$ than in the remaining participants $(M=3.33, S D=1.62), t(481)=-6.45, p<.001$. The sports science students were selected not only because they were expected to report significantly higher levels of vigorous physical activity than the remaining participants but also because exercise is likely to constitute a more significant part of their lives relative to the other participants and therefore to be more closely tied to their non-contingent self-concept (Sheldon, 2004). The student samples were convenience samples and members of the general population were recruited through self-selected sampling upon receiving information about the study. Participants were recruited through course convenors, group leaders, and business managers using mail, email and telephone correspondence. All participants provided data on the regulatory constructs and past physical activity, while a sub-sample $(\mathrm{N}=310)$ provided data on measures of life satisfaction, subjective vitality, and facets of flow. A sub-sample of the loweractive sample $(\mathrm{N}=153$, Males $=38$, Females $=115, M$ age $=23.60, S D=10.21)$ provided follow-up behavioural data for exercise at the second wave of data collection. The behavioural data were collected within a parallel study exploring the predictive validity of integrated regulation and were provided by $87 \%$ of the 176 individuals who received the second questionnaire. Data from five participants were excluded overall because of a missing data rate in excess of $5 \%$, resulting in a final total sample of 483 participants.

\section{Design}

Cross-sectional surveys were employed for the expert-rater survey and confirmatory factor analyses. For the assessment of the predictive validity of integrated regulation, a prospective survey design was used.

\section{Measures}

Demographic variables. All participants were asked to self-report age, gender, and date of birth.

Behavioural regulations in exercise. Constructs from the regulatory continuum, with the exception of integrated regulation, were assessed through the revised Behavioural 
Regulation in Exercise Questionnaire (BREQ-2, Markland \& Tobin, 2004). Participants were required to endorse items on a 4-point Likert-type scale to represent their feelings about participating in leisure-time exercise, defined as including all sports and physical activities that were really active, such as swimming, jogging, and sports training. The response scale was anchored by not true at all (1) and very true (4). Intrinsic motivation items included "I enjoy exercise" $(\alpha=.87)$, identified regulation items included "I participate in exercise because I gain a lot of benefits that are important to me" $(\alpha=.84)$, introjected regulation items included "I will feel bad with myself if I do not exercise $(\alpha=.83)$, external regulation items included "I do it because significant others want me to exercise" $(\alpha=.80)$, and amotivation items included "I think exercising is a waste of time" $(\alpha=.86)$. The BREQ-2 subscales have also shown satisfactory internal reliabilities in past research, and confirmatory factor analyses of BREQ-2 data obtained from 194 former GP exercise referral scheme participants indicated that the model had an excellent fit to the data (Markland \& Tobin, 2004).

Expert-rater survey: Initial integrated regulation item pool. A pool of 19 items was developed to capture the essence of integrated regulation through an extensive literature search of previous studies that measured integrated regulation in the domains of, exercise, sport, and dieting (e.g., Pelletier et al., 2004; Mallett et al., 2007) and from a content analysis of definitions in the located literature. These items are shown in Table 1. The issue of content validity was attended to through careful selection of items to ensure representation of essential facets of integration and through the use of multiple expert judges in assessing the representativeness of the items in measuring the construct. A formal scaling procedure was employed in rating the representativeness of the items in accordance with Haynes, Richard, and Kubany's (1995) recommendations that scale items should capture all facets of the construct of interest, in this case, integration. Eight $\mathrm{PhD}$-trained psychologists, with high familiarity with SDT and psychometrics, working at several universities in the United Kingdom were contacted via email and informed about the purpose of the study and the expert survey that they were 
invited to complete. Of the experts approached, $75 \%$ agreed to assist with rating the content validity of items measuring the SDT motivational constructs. These experts were asked to rate each item for the degree to which it was representative of each of the six regulatory constructs from the continuum of behavioural regulation. Ratings were obtained on five-point Likert scales anchored by very unrepresentative (1) and very representative (5). Means and standard deviations for representativeness ratings were computed to identify those items rated as most representative of the integration construct. These ratings are provided in Table 1. Items pertaining to integrated regulation that received a rating of very representative of this construct from at least $80 \%$ of the experts were retained for further analysis. This resulted in items 1,2 , $3,5,6,7,13,15$, and 17 being retained. Two of these items (items 1 and 13) received the highest possible representativeness rating from all six SDT experts. For all further analyses, only these nine items rated as most representative of integrated regulation were included. For the expert-rater study, all items made reference to "a health behaviour". Ratings were made on a 5-point Likert type scale, anchored by not at all representative and very representative. Items in the main study referred specifically to sport and exercise activities that were highly active and included "I fully accept exercise as an activity which is truly my own", and "Doing exercise is a fundamental part of who I am".

Past exercise behaviour. A two-item measure of past leisure-time exercise was used. The measure was based on the methods of Bagozzi and Kimmel (1995) and Chatzisarantis, Hagger, Smith, and Phoenix (2004). The first item referred to leisure-time physical activity over the previous six months and the second to physical activity over the previous two weeks. Participants were asked to provide the frequency with which they had participated in active sports/vigorous physical activities during their leisure-time and indicated their responses on six-point Likert scales, anchored by not at all (1) and most of the days per week (6). Active sports/vigorous physical activities were stated as the target behaviours in order to reflect differences in activity level between the two sub-samples that may not have been revealed had 
moderate physical activity been the frame of reference. The construct, concurrent, and predictive validity of such self-report measures has been established in previous research (e.g., Cale, 1994; Chatzisarantis, Hagger, Biddle, \& Karageorghis, 2002; Hagger \& Chatzisarantis, 2005; Orbell, Hagger, Brown, \& Tidy, 2006).

Subjective vitality. Participants responded to Ryan and Frederick's (1997) subjective vitality scale. This scale consists of seven items, including "I feel alive and vital" and "I have energy and spirit". Participants rated the vitality items on 7-point scales, anchored by not at all true (1) and very true (7), in terms of how they applied to the participant and the participant's life at the present time. The construct and nomological validity of this scale was established by Ryan and Fredrick, and the measure was reported to correlate significantly with an index of self-determination.

Life satisfaction. Diener, Emmons, Larson and Griffin's (1985) Satisfaction with Life Scale (SWLS) was employed. The measure contains five items, including "In most ways my life is close to my ideal" and "I am satisfied with my life". Participants were asked to indicate their agreement with each item by circling the appropriate number on the 7-point Likert response scales provided. The response scale was anchored by strongly disagree (1) and strongly agree (7). The SWLS has demonstrated high internal consistency, temporal reliability and concurrent validity with other measures of subjective well-being (Diener et al., 1985).

Flow state scale. Participants completed items measuring the challenge-skill balance, paradox of control, action-awareness merging, and autotelic experience subscales from Jackson and Marsh's (1996) Flow State Scale (FSS) in relation to their exercise activities. These subscales were considered most closely conceptually related to integration. Example items from the FSS are "I was challenged, but I believed my skills would allow me to meet the challenge" (challenge-skill balance), "I felt in total control of what I was doing" (paradox of control), "I performed automatically" (action-awareness merging), and "I loved the feeling of that performance and want to capture it again" (autotelic experience).Participants were asked to 
respond to each item on a five-point Likert scale, anchored by strongly disagree (1) and strongly agree (5). Internal consistency estimates for the FSS were adequate when the scale was administered to a sample of 394 athletes and confirmatory factor analyses supported the hypothesised structure of the scale (Jackson \& Marsh, 1996).

Exercise behaviour. A two-item retrospective measure of exercise behaviour was used at the second wave of data collection and was based on the measure used by Hagger, Chatzisarantis, and Harris (2006). This measure referred to the four week period intervening between the completion of the initial questionnaire and the administration of the follow-up behavioural measure. Participants were informed that the two questions related to their leisuretime physical activity over the last four weeks, and this was defined as including all sports and physical activities that were highly active, such as swimming, jogging, and sports training. The items were "In the course of the past four weeks, how often have you participated in leisuretime physical activity for 20 minutes at a time?”, rated on a 6-point Likert-type scale with endpoints never (1) and everyday (6), and "I engaged in leisure-time physical activity for 20 minutes at a time the past four weeks with the following regularity", rated on a 6-point Likerttype scale with endpoints everyday (1) and almost never (6). The latter item was reverse coded. The measure is based on Godin and Shephard's (1985) brief measure of exercise behaviour. Factor analytic studies have supported the construct validity of such measures in indicating latent behavioural variables (Hagger \& Chatzisarantis, 2005) and the concurrent and criterion validity has been confirmed against more objective measures, for instance heart rate monitoring (Cale, 1994).

\section{Procedure}

Expert-rater survey. The expert-rater survey preceded the main study. Raters scored each item for the degree to which it was representative of each of the six regulatory constructs via an online survey. 
Main study. Participants completed the initial questionnaire in a quiet environment. For the undergraduate, postgraduate, and A-level students, this consisted of quiet class- or lecture-room conditions, while for the working adults, questionnaires were completed within the working environment. Adults within the community groups completed the questionnaires during group meetings. The questionnaire was presented as a survey on leisure-time exercise. In accordance with British Psychological Society ethical guidelines and the ethical procedures of [Institution omitted for masked review], participants provided informed consent, were informed of their right to withdraw from the study at any time, and all data were collected anonymously to preserve confidentiality. Participants were asked to consider the active sports and/or vigorous physical activities that they might do during their leisure-time and to respond to the questions using this conceptualisation. A definition of active sports and/or vigorous physical activities was provided. The behavioural follow-up measure was administered four weeks following the initial questionnaire. Data from the two waves were matched using anonymous identifiers.

\section{Data analysis}

To test the adequacy of the hypothesised models in accounting for the observed variance and covariance matrices and the construct and discriminant validity of the integrated regulation construct, confirmatory factor analyses (CFAs) were conducted using the EQS v.6.1 computer software (Bentler, 2004). Multi-sample invariance analyses were employed to test the invariance of the factor structure, factor loadings, factor variances, and factor covariances of the regulatory constructs across the high-active and lower-active samples. Latent means analyses were also conducted to test the invariance of factor intercepts and latent factor means across the samples. In order to protect model estimation from violations of the assumption of normality, a robust maximum likelihood method was employed (Satorra \& Bentler, 1988). Model fit was assessed using multiple indices of good fit: comparative fit index (CFI; Bentler, 1990), the non-normed fit index (NNFI; Marsh, Balla, \& McDonald, 1988), the standardised 
root-mean square of the residuals (SRMR; Hu \& Bentler, 1995), and the root-mean square error of approximation (RMSEA; Hu \& Bentler, 1999) with its $90 \%$ confidence intervals (90\% CI). For the latent means analysis, the McDonald fit index (MFI; McDonald, 1989) and Akaike's information criterion (AIC; Akaike, 1987) were used. The value of .90 has been suggested as the minimal indication of good fit for the CFI and NNFI indexes (Bentler, 1990), although $\mathrm{Hu}$ and Bentler (1999) proposed that values in excess of .95 as representative of a well-fitting model. For the SRMR and RMSEA, values below .08 and 0.5 respectively denote acceptable model fit (Hu \& Bentler, 1999). For the MFI, Hu and Bentler (1999) suggested a cutoff score of .89 in representing a well-fitting model, while smaller values for the AIC represent a better fit (Hu \& Bentler, 1995).

In terms of the multi-sample analyses, Cheung and Rensfold (2002) suggested that a change of -0.01 or less in incremental fit indices between baseline and subsequent constrained models supports equivalence across groups. The Lagrange Multiplier (LM) test was used to indicate fixed parameters within the model that would result in a significant change in the goodness-of-fit chi square if released. Finally, multiple regression analysis was conducted to assess the predictive validity of the integrated regulation measure. The predictive validity of the measure is of particular importance, given its intended use in illuminating the mediating mechanisms of behaviour change interventions.

\section{Results}

\section{Preliminary Analyses}

Missing data. Missing data points were resolved through multiple imputation from existing values for closely-related variables using methods advocated by Shafer and Graham (2002) for cases with less than 5\% missing data. Six cases with a missing data rate in excess of $5 \%$ were excluded from the analysis.

Internal reliability of integrated regulation construct. Cronbach's alpha $(\alpha)$ was 0.92 for integrated regulation, indicating excellent internal reliability. 


\section{Single Sample CFAs}

Development of integrated regulation scale items. A set of four core items measuring integrated regulation was developed on the basis of the nine items rated most representative by experts and using the data from the lower-active sample. The initial pool of 19 items, along with means and standard deviations for representativeness can be found in Table 1 . The nine items which received the highest rating of representativeness from $80 \%$ or more of the experts were set to load on a single latent factor for integrated regulation in physical activity. The loading of each indicant item on the latent factor, the item variance, and error terms associated with each item were freely estimated, except for one loading that was set to unity, as is convention (Jöreskog, 1993). The overall model exhibited good fit with the data, S-B $\chi^{2}=$ 78.96, $\mathrm{df}=27, p<.001 ; \mathrm{CFI}=.98 ; \mathrm{NNFI}=.97 ; \mathrm{SRMR}=.02 ; \mathrm{RMSEA}=.08,90 \% \mathrm{CI}$, lower bound $(\mathrm{LB})=.06$, upper bound $(\mathrm{UB}) .10$. No substantial misspecification was present in the model, as no standardized residuals exceeded 2.00. All nine items demonstrated satisfactory standardized factor loadings (median $\lambda=.88$, range .73 to .93 , median $\mathrm{R}^{2}=.77$ ), exceeding the recommended minimum of 0.400 (Ford, MacCallum, \& Tait, 1986) and the integrated regulation factor accounted for in excess of $50 \%$ of the variance in each of the items. Four items were selected for the final scale in order to provide a measure compatible with the BREQ-2. Items 2 ("It is essential to my identity and sense of self"), 7 ("It is genuinely part of me"), 13 ("It is consistent with my values, goals and aims in life"), and 17 ("Doing exercise and being myself are inseparable") were selected as the core set of items to assess integrated regulation. These four items were chosen because they exhibited substantial factor loadings and, most importantly, their content was deemed to capture the fundamental characteristics of integrated regulation, as described by Deci \& Ryan (2000) and Deci, Eghrari, Patrick, and Leone (1994). Only two of the four items with the greatest variance extracted and highest factor loadings were selected because of considerable overlap between three of these items in terms of the facets of integrated regulation represented. A further CFA for the four selected 
integrated regulation items was conducted, in which the items were set to load onto a single factor. This model exhibited good fit to the data, $\mathrm{S}-\mathrm{B} \chi^{2}=3.15$, df $=2, p=.21$; CFI = .998; $\mathrm{NNFI}=.995 ; \mathrm{SRMR}=.01 ; \mathrm{RMSEA}=.04,90 \% \mathrm{CI}=.00(\mathrm{LB}), .13(\mathrm{UB})$. These four items were therefore retained for the final integrated regulation scale.

Nomological and discriminant validity. This analysis tested the hypotheses that integrated regulation scale items would load solely on the expected latent factor in with no cross-loadings on factors representing intrinsic motivation and identified regulation (H1) and that a simplex-like pattern of relationships would emerge among the regulatory constructs (H2). A CFA model was specified with six factors representing the four-item integration scale and the subscales from the BREQ-2 for the lower-active sample. Correlations between the factors were free parameters in the model, as is convention in CFA models. Overall, the model showed adequate fit to the data, $\mathrm{S}-\mathrm{B} \chi^{2}=377.33, \mathrm{df}=174, p<.001 ; \mathrm{CFI}=.93, \mathrm{NNFI}=.91$; SRMR $=.06 ;$ RMSEA $=.06,90 \% \mathrm{CI}=.05(\mathrm{LB}), .07(\mathrm{UB})$. However, the Lagrange Multiplier (LM) test suggested a problem with the discriminant validity of integration item 13 (see Table 1 for description) with intrinsic motivation, as a cross-loading was apparent. Subsequent analyses indicated that the internal reliability of the scale was unaffected if this item was dropped $(\alpha=.92)$. Covariances among independent variables were examined to determine the existence of the simplex-like pattern among the six regulatory constructs and to ensure that integrated regulation was appropriately situated on the continuum. Factor covariances can be found in Table 2. The simplex-like pattern of the continuum of behavioural regulation was largely supported by the lower-active sample's data, as constructs situated in close proximity exhibited stronger and more positive correlations, while constructs situated at extreme ends of the continuum showed negative correlations. All regulatory constructs showed discriminant validity, as none of the $95 \%$ confidence intervals for the interfactor covariances encompassed unity (Anderson \& Gerbing, 1988). Integrated regulation was therefore distinct from its neighbouring constructs, namely intrinsic motivation and identified regulation. 


\section{Nomological and discriminant validity with theoretically-related constructs. This}

analysis tested the hypothesis that nomological validity for integrated regulation would be established through significant and positive associations of the construct with vitality, lifesatisfaction, and pertinent facets of flow but that discriminant validity would also be evident (H3). This was assessed by examining covariances between the subscale and theoreticallyrelated constructs in the lower-active sample. A model was specified with seven latent factors; integrated regulation, subjective vitality, the four facets of flow, and life satisfaction. Again, correlations between the factors were free parameters in the model. The model showed good fit to the data, $\mathrm{S}-\mathrm{B} \chi^{2}=515.01, \mathrm{df}=443, p=.01 ; \mathrm{CFI}=.96 ; \mathrm{NNFI}=.96 ; \mathrm{SRMR}=.06 ; \mathrm{RMSEA}=$ $.04,90 \% \mathrm{CI}=.02(\mathrm{LB}), .05(\mathrm{UB})$. Standardized factor loadings for the integrated regulation scale were satisfactory, and the variance accounted for by the latent factor exceeded the $50 \%$ minimum criterion for adequacy for all but one item (integration item 13). Factor covariances are shown in Table 3. Integrated regulation was significantly and positively associated with all constructs except life satisfaction. Discriminant validity for integrated regulation was also evident as none of the $95 \%$ confidence intervals for the interfactor covariances encompassed unity.

Cross-validation in the high-active sample. The CFA model testing the nomological and discriminant validity of the integrated regulation with the remaining regulatory constructs (H2) was cross-validated using the data of the high-active sample. As in the previous analyses, six factors were specified using the integration factor and items from the BREQ-2, and correlations between factors were freely estimated. This model showed adequate fit with the data, S-B $\chi^{2}=251.12, \mathrm{df}=174, p<.001 ; \mathrm{CFI}=.92 ; \mathrm{NNFI}=.90 ; \mathrm{SRMR}=.07 ; \mathrm{RMSEA}=.05 ;$ $90 \% \mathrm{CI}=.04(\mathrm{LB}), .06(\mathrm{UB})$. Factor covariances largely supported the simplex-like pattern of relationships for the regulatory constructs (Table 2). Discriminant validity was evident for all constructs, as none of the $95 \%$ confidence intervals for interfactor covariances encompassed unity. 
Cross-validation with theoretically-related constructs. The model testing the nomological and discriminant validity of the integrated regulation scale with life satisfaction, subjective vitality, and the four facets of flow (H3) was cross-validated in the high-active sample. The fit of the model was satisfactory, S-B $\chi^{2}=577.05, \mathrm{df}=443, p<.0001 ; \mathrm{CFI}=.94$; $\mathrm{NNFI}=.93 ; \mathrm{SRMR}=.06 ; \mathrm{RMSEA}=.04,90 \% \mathrm{CI}=.03(\mathrm{LB}), .05(\mathrm{UB})$. Factor covariances are given in Table 3. Integrated regulation was significantly and positively associated with subjective vitality and autotelic experience, but not with the remaining constructs. Despite positive associations with subjective vitality and autotelic experience, integrated regulation still exhibited discriminant validity.

\section{Regression Analysis}

Multiple regression analysis tested the hypothesis that integrated regulation would account for a significant proportion of variance in prospective exercise behaviour, beyond that accounted for by the other regulatory constructs and age (H4). Multiple regression using manifest variables, rather than structural equation analyses using latent variables, was used due to restrictions in sample size. This has the limitation of introducing a modicum of measurement error. However, as factors were very well specified with high factor loadings and average variance extracted in the CFAs, it is unlikely that the findings in analyses using manifest variables were substantially affected by this.

In the regression model, exercise as the dependent variable was regressed on the six regulatory constructs, namely intrinsic motivation, integrated, identified, introjected, and external regulations, and amotivation, and gender and age. The overall regression model was significant, $F(7,144)=8.84, p<.001, R^{2}=.30$. A total of $30.1 \%$ of variance in exercise behaviour was accounted for. The only significant independent predictor of exercise behaviour was integrated regulation, $\beta=.26, p<.05$. Collinearity diagnostics did not indicate any problems with multicollinearity, according to Bowerman and O'Connell's (1990) 
recommendations. The predictive validity of the integrated regulation measure was therefore supported for exercise.

\section{Multi-Sample CFAs}

Invariance analysis. Multi-sample CFA analyses were conducted to test the hypothesis that the structure of the model specifying integrated regulation and the remaining regulatory constructs would be invariant across the high-active sample and the lower-active sample, as evidenced through the minimum criteria of invariance of factor structure and factor loadings (H5). For invariance to be established, Byrne, Shavelson, and Muthén (1989) stated that invariance of factor loadings was the minimum acceptable criterion. In the first instance, a baseline model was estimated in the high-active and lower-active samples to determine whether the factor pattern for the regulatory constructs was invariant across samples. The same model was specified as in previous analyses, with six latent factors representing the six regulatory constructs and the same indicant items. This baseline model exhibited satisfactory fit to the data, supporting the feasibility of the factor pattern across samples, S-B $\chi^{2}=609.66$, $\mathrm{df}=346, \mathrm{p}<.001 ; \mathrm{CFI}=.93 ; \mathrm{NNFI}=.92 ; \mathrm{SRMR}=.07 ; \mathrm{RMSEA}=.06,90 \% \mathrm{CI}=.05(\mathrm{LB})$, .06 (UB). The second step constrained factor loadings to be equal across samples. This analysis yielded a good fit, $\mathrm{S}-\mathrm{B} \chi^{2}=642.34, \mathrm{df}=361, \mathrm{p}<.001 ; \mathrm{CFI}=.93 ; \mathrm{NNFI}=.92 ; \mathrm{SRMR}=.08$, $\mathrm{RMSEA}=.06,90 \% \mathrm{CI}=.05(\mathrm{LB})$. According to Cheung and Rensfold's (2002) invariance criterion, it was concluded that the factor loadings were invariant across the samples.

In the third step, factor variances were also constrained to be equal across groups. This model yielded suboptimal goodness-of-fit statistics, $\mathrm{S}-\mathrm{B} \chi^{2}=802.63, \mathrm{df}=367, \mathrm{p}<.001 ; \mathrm{CFI}=$ $.89 ; \mathrm{NNFI}=.87 ; \mathrm{SRMR}=.51 ; \mathrm{RMSEA}=.08,90 \% \mathrm{CI}=.08(\mathrm{LB}), .09(\mathrm{UB})$. As incremental fit indices showed a decrease well in excess of Cheung and Rensfold's .01 criterion, some degree of noninvariance was apparent. Examination of the LM-test for releasing constraints indicated that the factor variances for intrinsic motivation, integrated regulation, identified regulation, 
introjected regulation, and amotivation were non-invariant. This indicates that the two groups were not using the same range of responses to these constructs.

In the final stage, factor covariances were constrained to be equal across the groups. This resulted in a model that exhibited inadequate fit with the data, $\mathrm{S}-\mathrm{B} \chi^{2}=875.43$, df $=382, \mathrm{p}$ $<.001 ; \mathrm{CFI}=.87 ; \mathrm{NNFI}=.86 ; \mathrm{SRMR}=.35 ; \mathrm{RMSEA}=.07,90 \% \mathrm{CI}=.07(\mathrm{LB}), .08(\mathrm{UB})$. The LM-test indicated that the covariance between intrinsic motivation and introjected regulation and the covariance between integrated regulation and amotivation were non-invariant. These findings suggest that the interfactor covariances were different across the groups and that the regulatory constructs may have been more differentiated in the high- active than the loweractive sample.

Latent means analysis. A latent means analysis was performed to test the hypothesis that the high-active sample would report significantly higher integrated regulation than the lower-active sample (H6). This analysis tests for differences in the latent means of factors across groups by evaluating the invariance of the reproduced indicator item means (intercepts) and latent variable means. Model comparisons were evaluated using the AIC, ECVI, and RMSEA indices of fit. A baseline model was specified such that items loaded onto their respective factors in the same way as the previous CFA models for the regulatory continuum, but with a constant specified within each equation. Variances were freely estimated for disturbance and error terms and constraints were specified to restrict factor loadings as invariant across the groups, as parameters determined as invariant in the multi-sample analysis should be retained in latent means analyses. This initial model exhibited satisfactory fit with the data, $\mathrm{S}-\mathrm{B} \chi^{2}=540.62, \mathrm{df}=349, p<.001 ; \mathrm{AIC}=-157.38 ; \mathrm{MFI}=.82 ; \mathrm{SRMR}=.08 ;$ $\mathrm{RMSEA}=.05,90 \% \mathrm{CI}=.04(\mathrm{LB}), .06(\mathrm{UB})$, indicating that the pattern of structured means was supported across the groups.

In the next step of the latent means analysis, item intercepts were constrained to zero. Consistent with the baseline model, factor loadings were constrained as invariant across the 
groups. The resultant model exhibited adequate fit with the data, $\mathrm{S}-\mathrm{B} \chi^{2}=582.52, \mathrm{df}=355, p<$ $.001 ; \mathrm{AIC}=-127.48 ; \mathrm{MFI}=.79 ; \mathrm{SRMR}=.08 ; \mathrm{RMSEA}=.05,90 \% \mathrm{CI}=.04(\mathrm{LB}), .06(\mathrm{UB})$ and suggested that there were few substantive differences in the intercept means across samples. The lower-active sample was designated as the reference group for comparisons (Byrne, 1994). Comparisons revealed that the high-active students rated the intrinsic motivation (latent mean difference $(\mathrm{LMD})=24.31, \mathrm{SE}=.07, p<.01)$, integrated $(\mathrm{LMD}=$ $35.09, \mathrm{SE}=.04, p<.01)$, identified $(\mathrm{LMD}=26.41, \mathrm{SE}=.07, p<.01)$, introjected $(\mathrm{LMD}=$ 40.87, $\mathrm{SE}=.04, p<.01)$, and extrinsic regulation $(\mathrm{LMD}=16.18, \mathrm{SE}=.05, p<.01)$, and amotivation $(\mathrm{LMD}=4.98, \mathrm{SE}=.10, p<.01)$ scales higher than the lower-active sample.

In the final latent means analysis model, both factor intercepts and means were constrained as invariant across the groups. This model exhibited satisfactory fit with the data, $\mathrm{S}-\mathrm{B} \chi^{2}=819.35, \mathrm{df}=370, \mathrm{p}<.001 ; \mathrm{AIC}=79.35, \mathrm{MFI}=.63, \mathrm{SRMR}=.18 ; \mathrm{RMSEA}=.07$, $90 \% \mathrm{CI}=.06(\mathrm{LB}), .08(\mathrm{UB})$. However, a decrement in fit was evident in comparison to the original baseline model as the AIC was substantially larger in this constrained model. The LMtest for releasing constraints revealed that releasing the six parameters constraining the latent means of the six factors as invariant across the groups would result in a substantial increase in goodness-of-fit of the model. This corroborated the mean comparisons made in step 2, supporting the significantly higher mean levels for the behavioural regulation factors in each sample.

\section{Discussion}

The present study adopted a rigorous, a priori, hypothesis-testing confirmatory factor analytic approach to the development of an integrated regulation scale for use in exercise context. The integrated regulation scale was developed from first principles as a mark of rigor to ensure that the various facets of integrated regulation, as defined by Deci and Ryan (2000) and Deci and colleagues (1994), were captured. The initial item pool was developed from an exhaustive literature search to identify previous measures and definitions of integrated 
regulation in the, exercise, sport, and dieting domains. Six experts in SDT rated the nineteen items for their representativeness of integrated regulation and four of the most highly rated items were selected for the final scale, on the basis of their capturing the essence of integrated regulation. This focus on the face validity of items in representing the underlying construct follows Wilson and co-workers' (2006) recommendation that further research on the development of measures of behavioural regulation for exercise should closely examine itemcontent relevance and the representation of constructs.

The newly-developed four-item integrated regulation scale exhibited factorial validity through a series of confirmatory factor analyses. Although there was some cross-loading of one item (item 13) with intrinsic motivation, this item was retained because it represents a fundamental aspect of integration and reflects Deci and Ryan's (2000) definition of the assimilation process as bringing identified regulations into congruence with other values and needs. This item also received the highest representativeness rating from all six expert judges. A simplex-like structure was evident for the regulatory constructs, with integrated regulation emerging as appropriately situated on the continuum, i.e., factor covariances were positive and strongest with its neighbouring constructs, while negative associations were apparent with constructs located at the distal end of the continuum. Nomological validity for the integrated regulation scale was also supported through confirmatory factor analyses specifying latent factors representing six constructs theoretically-related to integrated regulation alongside the latent integrated regulation factor.

The integrated regulation factor also exhibited positive and significant covariances with five of these theoretically-related constructs in the lower-active sample and with two of these constructs in the high-active sample. The finding of smaller effect sizes for the covariances between integrated regulation and the six theoretically-related constructs in the high-active sample than in the lower-active sample could reflect that integrated regulation is more fully 
developed in the high-active individuals and therefore more distinct from other related constructs in this population.

Importantly, the integrated regulation factor covaried positively and significantly with facets of flow, which has been viewed as an important motivational consequence by researchers adopting a SDT perspective (e.g., Kowal \& Fortier, 1999). Despite significant factor covariances, none of the covariance confidence intervals encompassed unity, thus discriminant validity was also established for the integrated regulation scale. Crucially, discriminant validity was demonstrated between integrated regulation and the two other most autonomous forms of regulation from SDT, namely, intrinsic motivation and identified regulation, which have frequently been found not to be statistically discriminable in previous research in sport and exercise (e.g., Lonsdale et al., 2008; Mallett et al. 2007).

Multi-sample invariance analyses supported the invariance of the factor pattern and factor loadings for the regulatory constructs for across the high-active and lower-active samples, thereby confirming the factorial validity of the integrated regulation scale. However, factor variances and covariances did not demonstrate invariance across the samples. The differing patterns of covariance between regulatory constructs in the two samples may reflect that the intrinsic, integrated, and identified constructs are more differentiated in high-active individuals. Further support for the validity of the scale was provided through latent means analysis. The current study represents the first direct comparison of latent means for regulatory constructs pertaining to exercise behaviour across high- and lower-active samples. Latent mean estimates indicated that the high-active sample reported significantly greater levels of integrated regulation than the lower-active sample, which is consistent with exercise becoming assimilated with the self and constituting an integral part of the lifestyle of the former group. The latent mean estimates also revealed that the high-active group reported significantly higher levels in the other regulatory constructs. Although it may initially appear counterintuitive that high-active individuals would report significantly higher levels of controlling motivation than 
individuals for whom exercise may be less fundamentally important and self-defining, it is feasible that they may be more motivated to avoid the shame and guilt associated with inactivity, to obtain self-worth from engaging in exercise and to attain tangible rewards associated with exercise and sport, which could underlie these elevated levels of introjected and external regulations. The finding that amotivation was also significantly higher in the highactive than the lower-active group is contrary to expectations and difficult to interpret on the basis of current data. To speculate, amotivation reflects non-intentionality with respect to behaviour and is supposed to represent a lack of motivation. However, one possibility is that people who are intrinsically motivated may endorse these items because they reflect the spontaneous attraction that behaviours that are intrinsically appealing have for such individuals. For example, sports participants may not know why they are intrinsically attracted to sports, but they are and it satisfies their needs. To coin a phrase, they "just do it". This may therefore reflect less conscious, implicit motivational factors that lead to behavioural engagement, which has been the focus of recent research (Burton, Lydon, D'Alessandro, \& Koestner, 2006; McLachlan \& Hagger, 2010, in press).

In terms of the predictive validity of the scale, integrated regulation emerged as the only significant independent predictor of exercise behaviour in a sub-sample of the loweractive individuals. Results therefore not only suggest that integrated regulation is a valid construct in this domain, in contrast to the assumptions of much previous research (e.g., Pelletier et al., 1995) but also that it is predictive of exercise behaviour, consistent with the findings of Wilson and colleagues (2006). However, the measure of integrated regulation in the present study confers advantages over that developed by Wilson and colleagues as it was developed from first principles to ensure representation of the essence of the integrated regulation construct and rigorously validated in a more diverse sample. Further, the present study provided greater evidence for the nomological validity of the scale. 
The measure of integrated regulation developed in the present paper has great potential as a means to assess the extent to which controlling forms of regulation are internalised and become integrated into a person's repertoire of behaviours to satisfy fundamental psychological needs. Given the importance of autonomous forms of motivation, such as integrated regulation, in predicting behavioural persistence and quality and psychological wellbeing in exercise (e.g., Standage, Duda \& Ntoumanis, 2005; Thøgersen-Ntoumani \& Ntoumanis, 2006), the development of a valid measure of this construct is essential in evaluating interventions targeted at changing motivation for exercise. Incorporating the present measure of integrated regulation within SDT-based questionnaires for exercise will also increase the fidelity of measurement instruments in SDT. Although Lonsdale and colleagues (2008) incorporated a measure of integrated regulation in their behavioural regulation in sport (BRSQ) instrument, they advised against the use of this measure in an exercise context, as it was specifically developed for use with competitive sports participants, and recommended context-specific instruments. The present study meets that need by providing a valid measure of integrated regulation and situating it amongst established measures of the other regulatory constructs from OIT to facilitate the comprehensive measurement of behavioural regulation in exercise.

\section{Limitations, Conclusions and Recommendations for Further Research}

The development of the integrated regulation measure focused on establishing initial validity of the instrument and did not assess forms of reliability beyond the internal consistency. Future research should assess the test-retest reliability of the scale and subject the measure to further tests of validity, for example employing the discriminant content validity method developed by Dixon, Pollard, and Johnston (2007). Further, results on the prediction of prospective exercise behaviour should be interpreted with a degree of caution until findings are replicated using more objective measures of behaviour, as common method variance may have artificially inflated the relationships (Pedhazur \& Schemlkin, 1991). It is also acknowledged 
that scale item 13 was problematic as a cross-loading with the intrinsic motivation factor was observed in one confirmatory factor analysis. Additionally, the variance in this item accounted for by the latent factor did not exceed the $50 \%$ minimum criterion for adequacy in a further analysis. However, this item was retained because it represented a fundamental characteristic of integrated regulation and received the highest rating of representativeness from all expert judges.

The present study was limited by the adoption of correlational and cross-sectional research designs. It would be valuable to employ cross-lagged panel designs in future studies utilising the integrated regulation subscale to assess the dynamics of integrated regulation over time. It would also be important to employ the scale alongside interventional methods manipulating autonomy support in exercise to examine the sensitivity of the scale to measuring the internalisation process and the role of integrated regulation as a mediator of behaviour change. Further, although efforts were made to avoid exclusive reliance on a student sample in the development of the measure, it is acknowledged that the majority of participants were students and the generalisability of findings should be considered with respect to the makeup of the current sample.

Nevertheless, the present study has provided evidence to support the validity of the integrated regulation scale for exercise, demonstrated its structural invariance across two diverse samples, its ability to distinguish between high-active and lower-active samples, and has provided some support for its predictive utility. 


\section{References}

Abraham, C., \& Michie, S. (2008). A taxonomy of behavior change techniques used in interventions. Health Psychology, 27, 379-387.

Akaike, H. (1987). Factor analysis and AIC. Psychometrika, 52, 317-332.

Anderson, J. C., \& Gerbing, D. W. (1988). Structural equation modeling in practice: A review and recommended two-step approach. Psychological Bulletin, 103, 411-423.

Bagozzi, R. P., \& Kimmel, S. K. (1995). A comparison of leading theories for the prediction of goal directed behaviors. British Journal of Social Psychology, 34, 437-461.

Bentler, P. M. (1990). Comparative fit indices in structural models. Psychological Bulletin, 107, 238-246.

Bentler, P. M. (2004). EQS structural equations modeling software (Version 6.1) [Computer software]. Encino, CA: Multivariate Software.

Blair, S. N., \& Brodney, S. (1999). Effects of physical inactivity and obesity on morbidity and mortality: current evidence and research issues. Medicine \& Science in Sports \& Exercise, 31, Suppl., S646-S662.

Bollen, K. A., \& Long, J. S. (Eds.). (1993). Testing structural equation models. Newbury Park, CA: Sage.

Bowerman B.L., O’Connell R. T. (1990). Linear statistical models: An applied approach, 2nd edition. Belmont, CA: Duxbury Press.

Burton, K. D., Lydon, J. E., D'Alessandro, D., \& Koestner, R. (2006). The differential effects of intrinsic and identified motivation on well-being and performance: Prospective, experimental, and implicit approaches to self-determination theory. Journal of Personality and Social Psychology, 91, 750-762.

Byrne, B. M., Shavelson, R. J., \& Muthe'n, B. (1989). Testing for the equivalence of factor covariance and mean structures: The issue of partial measurement invariance. Psychological Bulletin, 105, 456-466. 
Cale, L. (1994). Recommendations and new directions for the future development of children's self-report measures of physical activity. Health Education Journal, 53, 439-453.

Chatzisarantis, N. L. D., \& Hagger, M. S. (2009). Effects of an intervention based on selfdetermination theory on self-reported leisure-time physical activity participation. Psychology \& Health, 24, 29-48.

Chatzisarantis, N. L. D., Hagger, M. S.., Biddle, S. J. H., \& Karageorghis, C. (2002). The cognitive processes by which perceived locus of causality predicts participation in physical activity. Journal of Health Psychology, 7, 685-699.

Chatzisarantis, N. L. D., Hagger, M. S., Smith, B., \& Phoenix, C. (2004). The influences of continuation intentions on execution of social behaviour within the theory of planned behaviour. British Journal of Social Psychology, 43, 551-583.

Cheung, G. W., \& Rensfold, R. B. (2002). Evaluating goodness-of-fit indexes for testing measurement invariance. Structural Equation Modeling, 9, 233-255.

Cogan, J. C. \& Rothblum, E. D. (1993). Outcomes of weight-loss programs. Genetic, Social and General Psychology Monographs, 118, 385-415.

Csikszentmihalyi, M. (1975). Beyond boredom and anxiety. San Francisco: Jossey-Bass.

Csikszentmihalyi, M. (1990), Flow: The Psychology of Optimal Experience, New York: Harper and Row.

Csikszentmihalyi, M. (1993). The evolving self: A psychology for the third millenium. New York: HarperCollins.

D’Angelo, M. S., Reid, R. D., \& Pelletier, L. G. (2007). A model for exercise behaviour change regulation in patients with heart disease. Journal of Sport \& Exercise Psychology, 29, 208-224.

Deci, E. L. (1975). Intrinsic motivation. New York, US: Plenum Press.

Deci, E. L., Eghrari, H., Patrick, B. C., \& Leone, D. R. (1994). Facilitating internalization: The self-determination theory perspective. Journal of Personality, 62, 119-142. 
Deci, E. L., \& Ryan, R. M. (1991). A motivational approach to self: Integration in personality. In R. Dienstbier (Ed.), Nebraska symposium on motivation: Perspectives on motivation (Vol. 38, pp. 237-288). Lincoln: University of Nebraska Press.

Deci, E. L., \& Ryan, R. M. (2000). The "what" and "why" of goal pursuits: Human needs and the self-determination of behavior. Psychological Inquiry, 11, 227268.

Department of Health (2004). Choosing Health? Choosing activity: A consultation on how to increase physical activity. London: Department of Health/ Department of Culture Media and Sport.

Diener, E., Emmons, R. A., Larsen, R. J., \& Griffen, S. (1985). The satisfaction with life scale. Journal of Personality and Assessment, 49, 71-76.

Dixon, D., Pollard, B., \& Johnston, M. (2007). What does the chronic pain grade questionnaire measure? Pain, 130, 249-253.

Edmunds, J., Ntoumanis, N., \& Duda, J. L. (2006). A test of self-determination theory in the exercise domain. Journal of Applied Social Psychology, 36, 2240-2265.

Fairchild, A. J., Horst, S. J., Finney, S. J., \& Barron, K. E. (2005). Evaluating existing and new validity evidence for the Academic Motivation Scale. Contemporary Educational Psychology, 30, 331-358.

Ford, J. K., MacCallum, R. C., \& Tail, M. (1986). The applications of exploratory factor analysis in applied psychology: A critical review and analysis. Personnel Psychology, 39, 291-314.

Garner, D. M., \& Wooley, S. C. (1991). Confronting the failure of behavioral and dietary treatments for obesity. Clinical Psychology Review, 11, 729-780.

Godin, G., \& Shephard, R. J. (1985). A simple method to assess exercise behavior in the community. Canadian Journal of Applied Sport Science, 10, 141-146. 
Hagger, M. S. (2010). Health Psychology Review: Advancing theory and research in health psychology and behavioural medicine. Health Psychology Review, 4, 1-5.

Hagger, M. S., \& Chatzisarantis, N. L. D. (2005). First- and higher-order models of attitude, normative influence, and perceived behavioural control in the theory of planned behaviour. British Journal of Social Psychology, 44, 513-535.

Hagger, M. S., Chatzisarantis, N. L. D., \& Biddle, S. J. H. (2002). The influence of autonomous and controlling motives on physical activity intentions within the theory of planned behaviour. British Journal of Health Psychology, 7, 283-297.

Hagger, M. S., Chatzisarantis, N. L. D., \& Harris, J. (2006). From psychological need satisfaction to intentional behavior: Testing a motivational sequence in two behavioral contexts. Personality and Social Psychology Bulletin, 32, 131-148.

Hagger, M. S., Wood, C., Stiff, C., \& Chatzisarantis, N. L. D. (2009). The strength model of self-regulation failure and health-related behavior. Health Psychology Review, 3, 208238.

Hagger, M. S., Wood, C., Stiff, C., \& Chatzisarantis, N. L. D. (2010). Ego-depletion and the strength model of self-control: A meta-analysis. Psychological Bulletin, 136, 496-525.

Harrison, R. A., McElduff, P., \& Edwards, R. (2006). Planning to win: Health and lifestyles associated with physical activity amongst 15,423 adults. Public Health, 120, 206-212.

Haynes, S. N., Richard, D. C. S., \& Kubany, E. S. (1995). Content validity in psychological assessment: A functional approach to concepts and methods. Psychological Assessment, $7,238-247$.

Heatherton, T. F. (1993). Body dissatisfaction, self-focus, and dieting status among women. Psychology of Addictive Behaviors, 7, 225-231.

Hu, L., \& Bentler, P. M. (1999). Cutoff criteria for fit indexes in covariance structure analysis: Conventional criteria versus new alternatives. Structural Equation Modeling, 6, 1-55. 
Hu, G., Tuomilehto, J., Silventoinen, K., Barengo, N. C., Pettonen, M., \& Jousilahti, P. (2005). The effects of physical activity and body mass index on cardiovascular, cancer and allcause mortality among 47212 middle-aged Finnish men and women. International Journal of Obesity, 29, 894-902.

Ingledew, D. K., Markland, D., \& Sheppard, K. E. (2004). Personality and self-determination of exercise behaviour. Personality and Individual Differences, 36, 1921-1932.

Jackson S. A., \& Csikszentmihalyi, M. (1999). Flow in sports: The keys to optimal experiences and performances. Champaign, IL: Human Kinetics.

Jackson, S. A. and Marsh, H. W. (1996). Development and validation of a scale to measure optimal experience: The flow state scale. Journal of Sport and Exercise Psychology, 18, 17-35.

James, P. T., Rigby, N., \& Leach, R. (2004). The obesity epidemic, metabolic syndrome and future prevention strategies. European Journal of Cardiovascular Prevention and Rehabilitation, 11, 3-8.

Joreskog, K. G. (1993). Testing structural equation models. In K. A. Bollen and J. S. Long, (Eds.). Testing structural equation models, pp. 294-316. Newbury Park CA: Sage.

Kowal, J., \& Fortier, M. S. (1999). Motivational determinants of flow: Contributions from selfdetermination theory. The Journal of Social Psychology, 139, 355-368.

Kuczmarski, R. J., Flegal, K. M., Campbell, S. M., \& Johnson, C. L. (1994). Increasing prevalence of overweight among US adults: The National Health and Nutrition Examination Surveys, 1960 to 1991. Journal of the American Medical Association, 272, 205-211.

Li, F. (1999). The exercise motivation scale: Its multifaceted structure and construct validity. Journal of Applied Sport Psychology, 11, 97-115. 
Lonsdale, C., Hodge, K., \& Rose, E. A. (2008). The behavioral regulation in sport

questionnaire (BRSQ): Instrument development and initial validity evidence. Journal of Sport \& Exercise Psychology, 30, 323-355.

Mallett, C. J. \& Hanrahan, S. J. (2004) Elite athletes: why does the 'fire' burn so brightly? Psychology of Sport and Exercise, 5, 183-200.

Mallett, C., Kawabata, M., Newcombe, P., Otero-Forero, A., \& Jackson, S. (2007). Sport motivation scale-6 (SMS-6): a revised six-factor sport motivation scale. Psychology of Sport and Exercise, 8, 600-614.

Markland, D., \& Tobin, V. (2004). A modification to the behavioural regulation in exercise questionnaire to include an assessment of amotivation. Journal of Sport \& Exercise Psychology, 26, 191-196.

Marsh, H. W., Balla, J. R., \& McDonald, R. P. (1988). Goodness-of-fit indexes in confirmatory factor analysis: The effect of sample size. Psychological Bulletin, 103, 391-410.

Marsh, H. W., Hau, K., \& Wen, Z. (2004). In search of golden rules: Comment on hypothesistesting approaches to setting cutoff values for fit indexes and dangers in overgeneralizing Hu and Bentler's (1999) findings. Structural Equation Modeling, 11, $320-341$

McDonald, R. P. (1989). An index of goodness-of-fit based on noncentrality. Journal of Classification, 6, 97-103.

McLachlan, S., \& Hagger, M. S. (2010). Associations between motivational orientations and chronically-accessible outcomes in leisure-time physical activity: Are appearancerelated outcomes controlling in nature? Research Quarterly for Exercise and Sport, 81, $102-107$

McLachlan, S., \& Hagger, M. S. (in press). The influence of chronically-accessible autonomous and controlling motives on physical activity within an extended theory of planned behaviour. Journal of Applied Social Psychology. 
Menard, S. (1995). Applied logistic regression analysis. Thousand Oaks, CA: Sage.

Mokdad, A. H., Ford, E. S., Bowman, B. A., Dietz, W. H., Vinicor, F., Bales, V. S., \& Marks, J. S. (2003). Prevalence of obesity, diabetes, and obesity-related health risk factors, 2001. Journal of the American Medical Association, 289, 76-79.

Mullan, E., Markland, D., \& Ingledew, D. K. (1997). A graded conceptualisation of selfdetermination in the regulation of exercise behavior: Development of a measure using confirmatory factor analytic procedures. Personality and Individual Differences, 23, 745-752.

Myers, R. H. (1990). Classical and modern regression with applications, 2nd edition. PWS Kent, Boston, MA.

Orbell, S., Hagger, M. S., Brown, V., \& Tidy, J. (2006). Comparing two theories of health behavior: A prospective study of non-completion of treatment following cervical cancer screening. Health Psychology, 25, 604-615.

Pedhazur E. J., \& Schmelkin L. P. (1991). Measurement, design, and analysis: An integrated approach. Hillsdale, NJ: Erlbaum; 1991.

Pelletier, L. G., Dion, S. C., D’Angelo, M. S., \& Reid, R. (2004). Why do you regulate what you eat? Relationships between forms of regulation, eating behaviors, sustained dietary behaviour change, and psychological adjustment. Motivation and Emotion, 28, 245277.

Pelletier, L. G., Fortier, M., Vallerand, R. J., \& Bri`ere, N. M. (2001). Associations among autonomy support, forms of self-regulation, and persistence: A prospective study. Motivation and Emotion, 25, 4, 279-306.

Pelletier, L. G., Fortier, M., Vallerand, R. J., Tuson, K. M., Bri`ere, N. M., \& Blais, M. R. (1995). The Sports Motivation Scale (SMS): A measure of intrinsic motivation, extrinsic motivation, and amotivation in sports. Journal of Sport and Exercise, 17, 3553. 
Pelletier, L. G., \& Sarrazin, P. (2007). Measurement issues in self-determination

theory and sport. In M. S. Hagger \& N. L. D. Chatzisarantis (Eds.), Intrinsic motivation and self-determination in exercise and sport (pp. 143-152). Champaign, IL: Human Kinetics.

Riddoch, C. J., Mattocks, C., Deere, K., Saunders, J., Kirkby, J., Tilling, K. et al. (2007). Objective measurement of levels and patterns of physical activity. Archives of Disease in Childhood, 92, 963-969.

Ryan, R. M., \& Deci, E. L. (2000). Self-determination theory and the facilitation of intrinsic motivation, social development, and well-being. American Psychologist, 55, 68-78.

Ryan, R. M., \& Frederick, C. M. (1997). On energy, personality, and health: Subjective vitality as a dynamic reflection of well-being. Journal of Personality, 65, 529-565.

Ryan, R. M., Frederick, C. M., Lepes, D., Rubio, N., \& Sheldon, K. M. (1997). Intrinsic motivation and exercise adherence. International Journal of Sport Psychology, 28, 335354.

Satorra, A., \& Bentler, P. M. (1988). Scaling corrections for chi-square statistics in covariance structure analysis. ASA Proceedings, Business and Economic Statistics Section (pp. 308-313). Washington, DC: American Statistical Association.

Schafer, J. L., \& Graham, J. W. (2002). Missing data: Our view of the state of the art. Psychological Methods, 7, 147-177.

Sheldon, K. M. (2004). The benefits of a "sidelong" approach to self-esteem need satisfaction: Comment on Crocker and Park (2004). Psychological Bulletin, 130, 421-424.

Standage, M., Duda, J. L., \& Ntoumanis, N. (2003). Predicting motivational regulations in physical education: The interplay between dispositional goal orientations, motivational climate and perceived competence. Journal of Sports Sciences, 21, 631-647.

Standage, M., Duda, J. L., \& Ntoumanis, N. (2005). A test of self-determination theory in school physical education. British Journal of Educational Psychology, 75, 411-433. 
Thøgersen-Ntoumani, C., \& Ntoumanis, N. (2006). The role of self-determined motivation in the understanding of exercise-related behaviours, cognitions and physical selfevaluations. Journal of Sports Sciences, 24, 393-404.

Vallerand, R. J. (2001). A hierarchical model of intrinsic and motivation in sport and exercise. In G. C. Roberts (Ed.), Advances in motivation in sport and exercise (pp. 263-320). Champaign, IL: Human Kinetics.

Wannamethee, G., \& Shaper, A. G. (1992). Physical activity and stroke in British middle aged men. British Medical Journal, 304, 597-601.

Wickham, C. A., Walsh, K., Cooper, C., Barker, D. J., Margetts, B. M., Morris, J., \& Bruce, S. A. (1989). Dietary calcium, physical activity, and risk of hip fracture: a prospective study. British Medical Journal, 299, 889-892.

Williams, G. C., McGregor, H. A., Sharp, D., Levesque, C., Kouides, R. W., Ryan, R. M., \& Deci, E. L. (2006). Testing a self-determination theory intervention for motivating tobacco cessation: Supporting autonomy and competence in a clinical trial. Health Psychology, 25, 91-101.

Wilson, P. M., \& Rodgers, W. M. (2004). The relationship between autonomy support, exercise regulations and behavioural intentions in women. Psychology of Sport \& Exercise, 5, 229-242.

Wilson, P. M., Rodgers, W. M., Loitz, C. C., \& Scime, G. (2006). "It's who I am...really!" The importance of integrated regulation in exercise contexts. Journal of Applied Biobehavioral Research, 11, 79-104. 
Table 1

Original Item Pool Measuring Integrated Regulation Pertaining toExercise Behaviour, with Means and Standard Deviations of Expert Ratings of Representativeness $(N=6)$

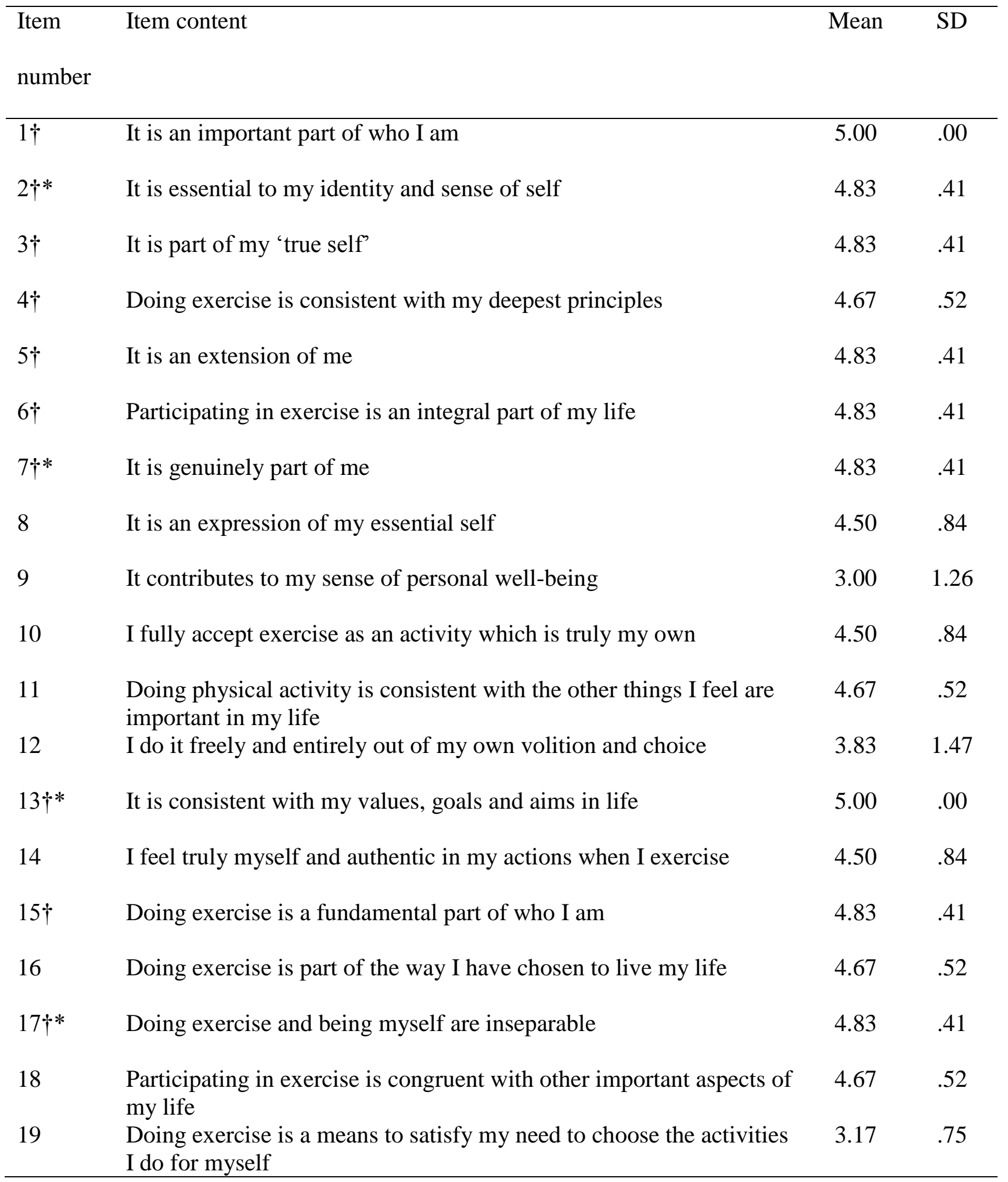

Note. $\dagger$ Item retained after expert ratings of representativeness; *Item retained for final fouritem integration scale. 
Table 2.

Covariances Among Factors Representing the Six Regulatory Constructs

\begin{tabular}{lcccccc}
\hline Regulation & 1 & 2 & 3 & 4 & 5 & 6 \\
\hline 1. Intrinsic motivation & - & $.12^{* *}$ & $.04^{* *}$ & $.06^{* *}$ & -.01 & $-.01 * *$ \\
2. Integrated regulation & $.47^{* *}$ & - & $.06^{* *}$ & $.18^{* *}$ & .01 & -.01 \\
3. Identified regulation & $.33^{* *}$ & $.30^{* *}$ & - & $.05^{* *}$ & .01 & -.01 \\
4. Introjected regulation & $.28^{* *}$ & $.31^{* *}$ & $.29 * *$ & - & $.10^{* *}$ & -.01 \\
5. External regulation & .02 & $.09^{* *}$ & .02 & $.15^{* *}$ & - & .01 \\
6. Amotivation & $-.15^{* *}$ & $-.06^{* *}$ & $-.17^{* *}$ & $-.12^{* *}$ & $.09 * *$ & - \\
\hline
\end{tabular}

Note. Coefficients below principal diagonal are for the sample comprising lower-active students and members of the general public $(\mathrm{N}=299)$ and above the principal diagonal for the high-active student sample $(\mathrm{N}=184) . * p<.05, * * p<.01$ 
Table 3

Covariances Among Factors Representing Integrated Regulation for Physical Activity, Life Satisfaction, Vitality, and the Four Facets of Flow

\begin{tabular}{lccccccc}
\hline Construct & 1 & 2 & 3 & 4 & 5 & 6 & 7 \\
\hline 1. Integrated regulation & - & .02 & $.19^{* *}$ & .05 & .05 & .03 & $.07^{*}$ \\
2. Life satisfaction & .15 & - & $.36^{* *}$ & $.15^{* *}$ & $.10^{*}$ & $.15^{* *}$ & $.13^{* *}$ \\
3. Subjective vitality & $.39^{* *}$ & $.53^{* *}$ & - & $.11^{* *}$ & $.08^{*}$ & $.13^{* *}$ & $.13^{* *}$ \\
4. Challenge-skill balance & $.23^{*}$ & .09 & $.25^{*}$ & - & $.15^{* *}$ & $.18^{* *}$ & $.18^{* *}$ \\
5. Action-awareness merging & $.23^{* *}$ & .02 & $.28^{* *}$ & $.34^{*}$ & - & $.21^{* *}$ & $.11^{* *}$ \\
6. Paradox of control & $.26^{* *}$ & $.19^{*}$ & $.38^{* *}$ & $.44^{*}$ & $.38^{* *}$ & - & $.20^{* *}$ \\
7. Autotelic experience & $.29^{* *}$ & $.20^{*}$ & $.31^{* *}$ & $.38^{*}$ & $.32^{* *}$ & $.43^{* *}$ & -
\end{tabular}

Note. Coefficients below principal diagonal are for the lower-active sample $(\mathrm{N}=299)$ and above the principal diagonal for the high-active sample $(\mathrm{N}=184) .{ }^{*} p<.05,{ }^{* *} p<.01$ 
Figure 1. An illustration of the SDT continuum of behavioural regulation applied to exercise behaviour (based on Hagger, Chatzisarantis, \& Biddle, 2002). 


\begin{tabular}{|c|c|c|c|c|c|}
\hline $\begin{array}{l}\text { Intrinsic } \\
\text { motivation } \\
\text { Exercise } \\
\text { behaviour } \\
\text { originates } \\
\text { with and } \\
\text { emanates } \\
\text { entirely from } \\
\text { the self. }\end{array}$ & $\begin{array}{l}\text { Integrated } \\
\text { regulation } \\
\text { Regulation for } \\
\text { exercise } \\
\text { behaviour has } \\
\text { been fully } \\
\text { assimilated } \\
\text { and is } \\
\text { consistent with } \\
\text { one's values, } \\
\text { beliefs, and } \\
\text { aspirations. }\end{array}$ & $\begin{array}{l}\text { Identified } \\
\text { regulation } \\
\text { Behavioural } \\
\text { engagement } \\
\text { for valued } \\
\text { outcomes } \\
\text { associated } \\
\text { with exercise. } \\
\text { Partial } \\
\text { internalisation } \\
\text { of regulation } \\
\text { and some } \\
\text { endorsement } \\
\text { from the self. }\end{array}$ & $\begin{array}{l}\text { Introjected } \\
\text { regulation } \\
\text { Behavioural } \\
\text { engagement to } \\
\text { avoid shame } \\
\text { and guilt or to } \\
\text { gain } \\
\text { conditional } \\
\text { self-worth. }\end{array}$ & $\begin{array}{l}\text { External } \\
\text { regulation } \\
\text { Exercise } \\
\text { behaviour } \\
\text { driven entirely } \\
\text { by external } \\
\text { contingencies, } \\
\text { for example } \\
\text { tangible } \\
\text { rewards and } \\
\text { externally } \\
\text { imposed } \\
\text { deadlines. No } \\
\text { sense of } \\
\text { ownership } \\
\text { over the } \\
\text { behaviour. }\end{array}$ & $\begin{array}{l}\text { Amotivation } \\
\text { The absence } \\
\text { of intention } \\
\text { or clear } \\
\text { motives to } \\
\text { engage in } \\
\text { exercise } \\
\text { behaviour. }\end{array}$ \\
\hline
\end{tabular}

